\title{
"DE MORALITATE EDUCACTIONE" ESTUDIO SOBRE LA MORALIDAD DE LA EDUCACIÓN CON EL MÉTODO DE TOMÁS DE AQUINO
}

Fabiola E. Saúl Gavito

\section{RESUMEN}

El presente estudio pretende explicar una operación esencial del hombre: el perfeccionamiento al que tiende por naturaleza, el cual debe ser guiado por un quehacer humano indispensable: la educación.

Para introducirnos al estudio de la educación, será necesario partir de la etimología de la palabra, pero ir más allá - trascendiéndola - para llegar a una definición que contemple todos sus elementos, tanto los señalados en la concepción clásica, como en la actualidad. El hilo teórico a seguir será la filosofía aristotélico-tomista, recogiendo los comentarios de algunos autores contemporáneos al Filósofo y al Aquinate, o bien, ideas que se deriven o concuerden con la doctrina realista. Todo ello mediante el método empleado por Santo Tomás en la Suma Teológica.

\section{INTRODUCCIÓN}

Bien es cierto que la educación es algo cotidiano en la vida del hombre y que es una palabra conocida por cualquiera. Pero en su uso corriente, suele referirse sólo a dos cosas: al proceso de enseñanza aprendizaje que transcurre dentro del aula de una escuela, o a los buenos modales recibidos de 
los padres o tutores. Así, suelen escucharse frases como: «Qué bueno que tu hijo puede recibir una buena educación en ese colegio!». O «ese niño grosero no tiene educación alguna!». A pesar de que ambos usos de la palabra sí hacen referencia a algunos elementos constitutivos de la educación, no expresan la riqueza o la profundidad del término (de hecho, se podría decir que lo reducen), por lo que a este uso de la palabra se le suele llamar significación vulgar.

En primer lugar, es necesario señalar que la etimología de la palabra "educación" consta de dos vocablos latinos; a saber: educare ("conducir", "guiar" o "criar", "alimentar") y educere ("sacar de", "extraer") ${ }^{1}$. El primero refiere a la necesidad de poseer una guía en el proceso educativo, así como a la necesidad de recibir algo, para poder recibir el influjo de la educación; puede decirse que tiene en cuenta la indigencia con la que nace el ser humano, que le hace requerir de otro que la ayude a recorrer su camino.

En cambio, el educere se enfoca a lo que el hombre ya posee dentro desde el principio, pues no podría "extraerse" nada de un recipiente o contenedor vacío. Hace referencia a las facultades que el hombre tiene y con las que cuenta para desarrollarse.

La síntesis de ambas significaciones puede comenzar a delinear algunas características de la educación. En primer lugar, que es un proceso dinámico mediante el cual se modifica al hombre (o se le ayuda a modificarse a sí mismo), pues se le debe llevar de un lugar a otro: no puede conducirse a alguien hacia el mismo lugar en que se encuentra. Y por otra parte, como ya se ha señalado, puede notarse claramente la necesidad de un otro que "guíe" o "extraiga", según el caso. Así, puede decirse hasta ahora que el proceso educativo es un extraer guiando o un conducir extrayendo. En otras palabras, es ayudar a que las facultades del hombre se mejoren, proporcionándole ayuda para saber cómo hacerlo, hacia dónde dirigirse, etcétera.

${ }^{1}$ García HOZ, V. Principios de Pedagogía Sistemática., p. 17. 
Asimismo, se encuentran en la doctrina tomista otros dos términos latinos relacionados con la educación: educatio (que él utiliza para designarla) se relaciona en gran medida con otros dos vocablos: nutritio e instructio ${ }^{2}$. Esto corrobora la relación de la educación con un cierto dar o nutrir (educare = "criar", "alimentar), mientras que el término instructio pone de relieve un elemento del que no se había hecho mención hasta ahora (salvo en la significación vulgar): una cierta sistematización de la educación (por eso también compara este término con el de disciplina), la cual no es otra cosa que la enseñanza.

Pero saber la etimología de la palabra no lleva a conocer por completo la naturaleza de la educación. A continuación se presenta un estudio filosófico del acto educativo, con miras a emitir un juicio moral sobre el mismo.

\section{NOTA DE LA AUTORA}

Sólo quisiera señalar que el hecho de escribir una cuestión de la Suma que además, no existe como tal, resultó para mí no sólo un reto sino una ilusión intelectual grande.

Reconozco que el método tomista de estudio no es fácil y que requiere una gran capacidad de síntesis y análisis. Esto explica las limitaciones de mi escrito en cuanto a la profundidad del estudio. Evidentemente, este trabajo no menoscaba ninguno otro hecho con anterioridad, especialmente el de dos textos que no puedo dejar de mencionar: el trabajo de Concepción Naval en torno a la educación en Aristóteles, Educación, Retórica y Poética, y el análisis exegético que Antonio Millán Puelles realiza de los textos del Aquinate en los que menciona la educación: La formación de la personalidad humana. Estas obras poseen una enorme seriedad académica y sin ellas no hubiera sido posible este trabajo.

Aun así, la ventaja del presente estudio realizado con este método en el siglo XXI, aproximadamente diez siglos después

\footnotetext{
${ }^{2}$ MILLÁN PUELLES, A. La formación de la personalidad humana., p. 23.
} 
de que Santo Tomás escribiera la Suma Teológica, es que pueden dialogar autores posteriores al Doctor Angélico, que además han ejercido una gran influencia en el pensamiento occidental; tal es el caso de Descartes en el área filosófica, y de Rousseau en el ámbito pedagógico.

Otra ventaja, es que ha podido hacerse uso del método fenomenológico, también producto de la filosofía contemporánea, y que es tan usado hoy en día por el hombre, aun sin que éste se dé cuenta.

Por último, quisiera señalar que el trabajo no ha seguido formato de una cuartilla normal, para darle un mayor parecido a la Suma. Esto explica el uso de dos columnas para el texto completo de la cuestión Sobre la moralidad del acto educativo.

\section{ARTÍCULO 1}

\section{¿LA EDUCACIÓN ES?}

Objeciones por las que parece que la educación no es en sentido estricto o por las que parece que no es un acto.

1. El ente es lo que es, y éste cuenta en su estructura con acto y potencia, por lo que puede pensarse que la educación, al ser un acto, no es sino una parte de la estructura de un ente, pero no es un ente, por lo que no es en sentido estricto.

2. Por lo mismo, al depender la educación de su sujeto, que es la persona, puede e innegable la existencia de un pensarse que ella es la sustancia y la educación es un accidente del género cualidad. Es decir, que la educación es un mero accidente y que una persona puede estar o no sin ella.

3. La educación no es un acto, pues si éste surge del movimiento, y como sostenía Parménides $^{3}$, el movimiento no existe, entonces la educación ni es un acto ni es en sentido estricto.

En cambio, resulta evidente 
sinnúmero de instituciones y leyes o normativas educativas, así como publicaciones sobre la educación, mismas que no pueden versar sobre un objeto que no existe.

Solución. Hay que decir que el hombre es un ser perfectible por naturaleza, es decir, que sus potencias espirituales, inteligencia y voluntad, aun cuando tienen un objeto propio al que están determinados - a saber, la verdad y el bien, respectivamente-, no están del todo determinados en cuanto que no los poseen todo el tiempo ni en plenitud. En este sentido, el hombre tiende a su propia perfección ${ }^{4}$.

"Hay, pues, una necesidad educativa en el hombre que le adviene constitutivamente. Esto es así porque las potencias más específicamente humanas, sus potencias operativas, están indeterminadas respecto a sus objetos propios, aunque poseen una capacidad de determinación mediante hábitos 5 .
Es por esta razón que el hombre está llamado a perfeccionarse mediante la adquisición de hábitos operativos buenos (virtudes) durante su existencia, con miras a alcanzar el bien que le es propio, la felicidad, y es precisamente la educación la que ayuda al hombre a realizarlo.

Evidentemente, si la educación es lo que ayuda a pasar del estado de perfectibilidad en el que no se poseen hábitos, se poseen pocos o se poseen en poca medida, por ende, la educación es necesariamente un acto.

En cuanto a su constitución metafísica, se puede decir que "el principio y el término del educar no son [...] otra cosa que situaciones de un ser esencialmente constituido, nunca la esencia o la sustancia misma de ese ser" ${ }^{6}$, pero, la importancia de la educación en cuanto tal es innegable, pues es precisamente la mejor ayuda para que el hombre alcance el fin que le es debido, de tal suerte que

\footnotetext{
${ }^{4}$ ARISTÓTELES, Metafísica, IX, 5, $1048 \mathrm{a}$.

${ }^{5}$ NAVAL, C., Educación, retórica y poética: Tratado de la educación en Aristóteles., p.48 ss.

${ }^{6}$ MILLÁN PUELLES, A. op. cit., p.35.
} 
sin ella corre un gran riesgo de no alcanzarlo.

Así, se podría definir la educación como el acto humano mediante el cual se ayuda a que el hombre quiera realizar los actos que le son propios a sus facultades (especialmente las espirituales), para que vaya completando paulatinamente su naturaleza a lo largo de su existencia, y con ello, alcance el fin que les propio: la felicidad. Se pretende esclarecer todos los elementos de esta definición a lo largo de la presente cuestión.

\section{Respuesta a las objeciones.}

1. A la primera bay que decir con el Filósofo que “(...) el Ente se dice no sólo en el sentido de "algo" o "cual" o "cuanto", sino también según la potencia y la entelequia y la obra (...), , de lo cual se deduce que el acto sí es y por lo tanto, la educación también.

2. A la segunda bay que decir que en cuanto tal, la educación efectivamente no forma parte de la sustancia de un ente y, por ende, vendría a constituir un accidente de la persona. Pero si se toma en cuenta que la educación ayuda al hombre a alcanzar el fin que le es propio y que tiene grabado en su esencia, entonces en sentido análogo la educación sería un proceso esencial en el hombre, pues sin él, éste no realiza su ser-hombre en plenitud.

3. A la tercera bay que decir que el movimiento "no es una novedad absoluta, un paso del no-ser al ser, sino el devenir de un sujeto desde un estado a otro" ${ }^{8}$, como por ejemplo el hielo que pasa a ser agua. Por tanto, existe el movimiento y en consecuencia, los actos. 


\section{ARTÍCULO 2 \\ ¿LA EDUCACIÓN ES UN ACTO HUMANO?}

Objeciones por las que parece que la educación no es un acto humano.

1. Si la educación ayuda a la consecución de hábitos, entonces no es necesariamente un acto humano, pues los animales también demuestran conductas habituales.

2. Si la educación es un proceso de perfeccionamiento al que está llamado el hombre por naturaleza, y éste es bueno por naturaleza, habría que decir con Rousseau' que el hombre no tiene que hacer nada para ser educado, pues es un acto natural al que tiende necesariamente.

3. Si las potencias espirituales tienden por naturaleza a perfeccionarse mediante la posesión de sus objetos propios, entonces basta con que se le presenten al hombre la verdad y el bien, para que inmediatamente los quiera $y$, con ello, se perfeccione. No hace falta una plena advertencia o una plena conciencia, por lo que la educación es un acto del hombre, no un acto humano.

En cambio, está lo que señala el Filósofo en De Ani$m a$, libro $\mathrm{V}$, que el perfeccionamiento que se da en el hombre como resultado del acto educativo, puede estructurarse en dos grandes direcciones: a) la que se produce en el orden de la inteligencia ${ }^{10}$ y b) la que pertenece al orden de la voluntad, manifestada, sobre todo, en la adquisición de hábitos ${ }^{11}$.

Solución. Hay que decir que el objetivo primero de la

${ }^{9}$ Ésta es la tesis central de Rousseau en el libro I del Emilio, pero la cita se tomó de MOREAU, J. Rousseau y la fundamentación de la democracia., p.42, en concreto de la sección donde, a la luz de las obras originales del autor, explica sus teorías educativas.

${ }^{10}$ ARISTÓTELES, De Anima, V, 417 b 15.

${ }^{11}$ ibidem, 417 b 16. Para esta cita y la anterior, cfr. también NAVAL, C. op. cit., p.77. 
educación es aquello que es más perfecto en el hombre, a saber, sus facultades espirituales, inteligencia y voluntad, pues "en la especie humana no sólo necesita el hijo de nutrición corporal, como en los demás animales, sino también instrucción en cuanto al alma ${ }^{12}$. Asimismo, se dijo (a. 1) que las potencias específicamente humanas están determinadas a su objeto, pero no lo poseen en plenitud, por lo que deben alcanzarlos por medio de la consecución de hábitos. En este sentido, la educación implica necesariamente ambas facultades.

Además, el acto humano implica voluntariedad, y ésta a su vez, implica conocimiento. Luego entonces, la educación es un acto humano, no sólo por parte de quien es educado (educando), sino también por parte de quien educa (educador), pues éste debe también conocer qué es la educación, quién es susceptible de ella y cómo se le puede educar, además de querer hacerlo.
Por lo tanto, la educación como acto humano puede recibir una calificación ética, es decir, es susceptible de juicio moral.

\section{Respuesta a las objeciones.}

1. A la primera bay que decir que el animal está sujeto a las potencias sensitivas, y éstas «están ordenadas [...] a una misma cosa ${ }^{13}$ es decir, necesariamente eligen el objeto al que están determinadas. En ese sentido el animal no puede ser sujeto de hábitos, pues actúa por instinto. Además, señala el Aquinate que "si se toma el hábito en orden a la operación, el alma es el principal sujeto de hábitos, en cuanto que el alma no está determinada a una sola operación, sino abierta a muchas, que es lo que se requiere para ser sujeto de hábitos ${ }^{14}$. Con lo señalado en relación a los animales, se entiende que lo que dice respecto al alma se puede aplicar únicamente al alma humana, cuyas potencias, a pesar de estar determinadas a un objeto específico, pueden no elegirlo. 
2. A la segunda bay que decir que puede haber distintas causas por las que el hombre no elija necesariamente el bien, aun sabiendo que no es algo bueno lo que elige. Estas causas pueden ser: la ignorancia ${ }^{15}$, la malicia ${ }^{16}$ o las pasiones del apetito sensitivo $^{17}$, es decir, la falta de bien en la inteligencia, en la voluntad o en los apetitos sensitivos, respectivamente. Por tanto, dejar que el hombre crezca "naturalmente" como el Emilio de Rousseau no implicará necesariamente que alcance la perfección a la que está llamado. En consecuencia, la educación no puede ser un acto natural.

3. A la tercera bay que decir que "a un conocimiento perfecto del fin sigue lo voluntario según su razón perfecta; puesto que, una vez aprehendido el fin, uno puede dirigirse hacia él o no, después de deliberar acerca del fin y de las cosas que se ordenan a él ${ }^{18}$, de lo que se sigue que para que la inteligencia y la voluntad se perfeccionen alcanzando sus objetos propios, se necesita conocimiento y voluntariedad. Luego entonces, sí se necesita plena advertencia para que se presente la educación.

\section{ARTÍCULO 3}

\section{¿SE PUEDE JUZGAR MORALMENTE EL ACTO EDUCATIVO DE MANERA GENÉRICA?}

Objeciones por las que parece que sí se puede juzgar el acto educativo de manera genérica.

1. Si la educación está dirigida al género humano, entonces se le puede juzgar moralmente de manera genérica.

${ }^{15}$ ibid., I-II, q. 76.

${ }^{16}$ ibid., I-II, q. 78.

${ }^{17}$ ibid., I-II, q. 77.

${ }^{18}$ ibid., I-II, q. 6, a 2, c.
2. Si la educación es un acto humano, luego entonces, puede ser juzgado moralmente de manera genérica.

En cambio, es un hecho innegable que para emitir un 
juicio moral sobre un acto, se hace en relación a una persona específica, misma que realizó el acto que pretende juzgarse en un momento, lugar y de un modo determinados. No se ha visto un juicio moral sobre algo que no haya hecho persona alguna.

Solución. Hay que decir que existen tres elementos para juzgar los actos humanos, a saber, objeto, circunstancias y fin $^{19}$. El objeto es aquello que nombra al acto, el fin es lo último en la ejecución (aun cuando haya sido lo primero en la intención). Si se habla de la educación in genere, ciertamente se podría llegar a conocer el objeto y el fin de la educación de manera genérica.

Pero si las circunstancias son los «accidentes individuales de los actos humanos ${ }^{20}, \mathrm{y}$ el conocimiento humano necesariamente parte de los individuales, de las cualidades sensibles de un objeto concreto, pues "la sensación [...] es de lo singular ${ }^{21}$, de lo individual, entonces no se podrá conocer ni juzgar el acto educativo de manera genérica, sino que se tendrá que concretar al menos en las circunstancias, y eso es lo que se hará para poder emitir un juicio moral acerca de dicho acto.

\section{Respuesta a las objeciones.}

1. A la primera bay que decir que aun cuando sea el género humano a quien está dirigido el acto educativo, no es la humanidad quien educa, sino un hombre concreto. Luego entonces, no se puede juzgar el acto educativo de manera genérica.

2. A la segunda bay que decir que el acto humano tiene verificativo cuando es realizado por un sujeto, y el sujeto del acto humano es la persona. Por tanto, no puede juzgarse el acto humano genéricamente, sino sólo en cuanto es ejercido por una persona.

${ }_{19}$ ibid., I-II, q.q. 7, 8, 12.

${ }^{20}$ ibid., I-II, I-II, q. 7, a 1.

${ }^{21}$ ARISTÓTELES, De Anima., II, 12, 417b. 


\section{ARTÍCULO 4 \\ ¿EL OBJETO DEL ACTO EDUCATIVO ES \\ EL HECHO DE EDUCAR?}

Objeciones por las que parece que el objeto de la educación no es el hecho de educar.

1. Tal parece que si el objeto del conocimiento sensible son las cosas de la misma naturaleza, luego entonces el objeto de la educación debe ser aquello sobre lo que versan, a saber, las facultades espirituales del hombre. Entonces no puede decirse que el objeto de la educación sea el acto de educar.

2. Si el objeto de una acción es una cosa, entonces el objeto de la educación no puede ser un acto (que sería, según se propone, el hecho de educar) sino una cosa sensible.

En cambio, está lo que dice el Aquinate, que «(...) del mismo modo que la primera bondad de una cosa natural se aprecia en su forma, que le da la especie, así también la primera bondad de un acto moral se aprecia en su objeto conveniente ${ }^{22}$. Es decir, que el objeto es lo que especifica al acto y por ende, el hecho de educar es lo que da nombre al acto educativo.

Solución. Hay que decir que si el objeto es aquello que da forma al acto, y la forma es aquello que especifica el objeto, entonces, la forma del acto educativo es el hecho de educar. Asimismo, el objeto de un acto se puede ver no sólo como forma, sino también como materia, pues al ser la persona el sujeto del acto humano, y al poseer ésta materia, necesariamente los actos humanos implican materia. En el caso de la educación, la "materia" de la que se está hablando es la comunicación entre los hombres, pues sin ella no se podría ejercer ningún acto educativo.

Además, el objeto de un acto puede verse como término, entendido éste como "lo último de cada cosa, y lo primero fuera de lo cual no es

\footnotetext{
${ }^{22}$ DE AQUINO, T. op. cit., I-II, q. 18, a. 2, c.
} 
posible tomar nada de ella, y lo primero dentro de lo cual está todo lo de ella ${ }^{23}$. Esto hace alusión a la temporalidad a la que todos los actos están sujetos, pues la persona, que es de suyo temporal, es causa eficiente del acto humano. En este sentido, el término del acto educativo visto de manera genérica, puede abarcar toda la existencia humana.

\section{Respuesta a las objeciones.}

1. A la primera bay que decir que se introduce en ella una confusión semántica, pues en el ámbito psicológi$\mathrm{co}$, ciertamente se dice objeto del conocimiento, aquello sobre lo que versa, pero en el ámbito moral, el objeto es aquello que nombra al acto, pues como ya se dijo (sed contras), el acto recibe su forma por el objeto. Luego, sí se puede decir que el objeto del acto educativo sea el hecho de educar.

2. A la segunda bay que decir que si bien hay actos que pueden conocerse por una cosa sobre la que versan (tal es el caso del comer o del matar), el objeto de una acción, es, como se ha señalado, el núcleo del acto, aquello que le da forma, que no necesariamente debe ser una cosa sensible.

\section{ARTÍCULO 5}

\section{¿EL FIN DE LA EDUCACIÓN ES EL PERFECCIONAMIENTO DEL HOMBRE?}

Objeciones por las que pa- la educación no es el perfecrece que el fin de la educación cionamiento sino el hábito no es el perfeccionamiento bueno.

del hombre.

1. Si se ha explicado que el hombre necesita alcanzar su perfeccionamiento mediante la adquisición de hábitos (a. 2), entonces el fin de
2. La educación tiende a ayudar a que la inteligencia y la voluntad alcancen los objetos que les son propios. Luego entonces, el fin de la educación se centra solamente 
en dichas facultades espirituales, no en todo el hombre.

3. Si el fin de la existencia humana es la felicidad, misma que es alcanzada por el hombre cuando logra la plenitud o el perfeccionamiento, entonces el fin de la educación es la felicidad ${ }^{24}$, no el perfeccionamiento del hombre.

En cambio, es un hecho que un hombre que adquiere virtudes llega a ser un hombre feliz, como señala el Filósofo no sólo en sus obras sobre cuestiones éticas ${ }^{25}$, sino en toda su obra ${ }^{26}$. Luego, la educación se relaciona tanto con el perfeccionamiento como con la felicidad.

Solución. Hay que decir que la educación "conviene al hombre entero y no a una parte o aspecto en él, aunque también es cierto que [la educación] principalmente se refiere a la formación del alma humana ${ }^{27}$, cuyas facultades son la inteligencia y la voluntad.
Así, si en sentido amplio la educación está dirigida al perfeccionamiento de todas las facultades del hombre, entonces “(...) lo que se logra por la educación es que [el hombre] llegue al estado perfecto que en tanto que hombre le conviene. Importa pues, para entender de veras todo el sentido de la educación, observar que al hombre en tanto que hombre corresponde no sólo un ser perfecto que esencialmente hablando ya posee por el simple hecho de ser hombre [...], sino también un estado perfecto al que precisamente por ser hombre tiene que llegar ${ }^{28}$. Y es precisamente este estado perfecto el que el Filósofo denomina felicidad. En suma, puede decirse que el fin inmediato de la educación en sentido amplio es el perfeccionamiento del hombre y en sentido estricto, el perfeccionamiento de sus potencias espirituales, mientras que su fin mediato, es la felicidad del hombre ${ }^{29}$.

${ }^{24}$ cfr. ALTAREJOS, F. Educación y felicidad., p.24.

${ }^{25}$ Por ejemplo, cfr. ARISTÓTELES, Gran Ética, I, 4, 1185a.

${ }^{26}$ cfr. ARISTÓTELES, Política, IV, 3, 1325a.

${ }^{27}$ ALTAREJOS, F. op. cit., p. 25.

${ }^{28}$ ibid., p. 35.

${ }^{29}$ cfr. NAVAL, C., op. cit., p.59 ss; ALTAREJOS, F. op. cit., p.23 ss. 
Respuesta a las objeciones.

1. A la primera bay que decir que el hábito no es fin de la educación, sino su fuen$\mathrm{te}^{30}$, misma que, junto con la naturaleza y la razón son condiciones que hacen posible el acto educativo en el hombre. Por tanto, el hábito no es el fin de la educación.

2. A la segunda bay que decir que el hombre es una unidad sustancial de cuerpo y espíritu, por lo que la sola perfección de sus potencias espirituales sería una educación deficiente, si se pretende que por medio de este acto el hombre se perfeccione. Luego, el fin de la educación no puede centrarse solamente en la parte espiritual, sino que debe atender a la parte corporal (y por ende, a la sensitiva y la afectiva) también.

3. A la tercera bay que decir que ciertamente, el fin último del hombre es la felicidad, y ésta consiste en "el ejercicio y uso perfecto de la virtud, y ésta no por convención sin en absoluto" ${ }^{31}$, en cuya definición queda claro que la virtud es condición de la felicidad. Luego, es necesario que primero la educación ayude al hombre a ser virtuoso, para que logre como consecuencia la felicidad.

\section{ARTÍCULO 6 \\ ¿CUÁLES PUEDEN SER LAS CIRCUNSTANCIAS DEL ACTO EDUCATIVO?}

Objeciones por las que circunstancias del acto educapueden parecer confusas las circunstancias del acto educativo.

1. Si «se llama circunstancia a lo que existe fuera de la sustancia del acto y de algún modo lo afecta" ${ }^{32}$, puede parecer difícil estudiar las tivo, si éstas pueden variar de un acto a otro y siempre ser diferentes.

2. Si, como sostenía Descartes, existe una duda completa y radical, que no deja nada a salvo y por lo tanto, el

\footnotetext{
${ }^{30}$ cfr. NAVAL, C., op. cit., p.90 ss.

${ }^{31}$ ARISTÓTELES. Política., IV, 13, 1332 a 8-10.

${ }^{32}$ DE AQUINO, T. op. cit., I-II, q. 7, a.. 3 c.
} 
hombre para poder actuar debe crearse una moral provisional ${ }^{33}$, entonces no pueden conocerse las circunstancias del acto, porque todo se presenta como dudoso.

En cambio, está el estudio que hace el Filósofo acerca de los accidentes de las cosas materiales ${ }^{34}$, así como la clasificación que a partir de ello hace el Aquinate de las circunstancias del acto ${ }^{35}$.

Solución. Hay que decir que las circunstancias del acto son el efecto que produce, el tiempo, el lugar, el modo, la persona que lo realiza, la razón por la que lo hace, los medios que utiliza y la materia en la que lo hace ${ }^{36}$. Cada una de ellas responde a una pregunta.

Para permitir el juicio moral en el siguiente artículo, se concretarán, como se anunció en a. 3, las circunstancias en un acto educativo concreto respondiendo a cada pregunta. Este acto educativo se centrará en la educación sistematizada o formal porque puede resultar más claro como ejemplo.

- ¿qué? - estudiar la Maestría en Pedagogía.

- ¿cuándo? - en el ciclo escolar 2000-2002.

- ¿dónde?- en la Universidad Panamericana.

- ¿cómo? - asistiendo puntualmente a clases, cumpliendo con la normativa de evaluación señalada por la Facultad y por cada profesor en particular.

- ¿quién? - (causa eficiente) cualquier profesor autorizado por la Facultad.

- ¿por qué? - cubrir una necesidad de la institución donde se labora.

- ¿con qué medios? - mediante la acreditación de ciertas asignaturas y la presentación de un examen profesional - ¿acerca de qué? - (causa material) cualquier estudiante inscrito.

\footnotetext{
${ }^{33}$ Esto sustenta Desacartes en el Discurso del Método, pero la cita se tomó de CARDONA, C. René Descartes: El discurso del método., p.64.

${ }^{34}$ ARISTÓTELES. Metafísica., V, 1017b, 27 ss.

${ }_{35}$ DE AQUINO, T. op. cit., I-II, q. 7, aa 3, 4.

${ }^{36}$ ibid., I-II, q. 7, a 4, c.
} 
Respuesta a las objeciones. y que esa unidad sustancial

1. A la primera bay que se presenta como real al decir que la realidad tiene or- hombre mismo, por lo que su den y armonía, lo cual permi- actuar (al menos, su actuar te el estudio o clasificación externo) resulta tan cognoscide las circunstancias del acto, ble como cualquier objeto mismas que pueden aplicarse material. Así, la duda cartesiapara cualquier acto que se na no resulta un impedimenrealice.

to (y menos aún para el

2. A la segunda bay que filósofo realista) para conocer decir que el hombre es una las circunstancias del acto unidad sustancial de materia humano. (cuerpo ) y forma (espíritu) ${ }^{37}$,

\section{ARTÍCULO 7 \\ ¿EL ACTO EDUCATIVO ES BUENO?}

Objeciones por las que entonces la educación es un parece que la educación es acto moralmente malo, porque un acto moralmente malo o coarta la libertad del hombre. indiferente.

3. Según se ha dicho, el

1. Si metafísicamente la hombre tiende por naturaleza educación es un accidente, a su propio perfeccionamienentonces si se concreta en to, luego, la educación no una circunstancia no conve- sólo es innecesaria, sino que niente a la naturaleza del es un acto indiferente: el hombre, será un acto moral- hombre puede alcanzar la mente malo.

2. Si la educación hace que el hombre elija los mayores bienes, aquellos que mejor perfeccionan al hombre, pero éste no los quiere, seguirse que la educación sea ${ }^{37}$ cfr. ARISTÓTELES. op. cit., VIII, 1045 b. 
un acto malo, pues ayuda al hombre a la consecución de su fin último que es la felicidad.

Solución. Hay que decir que para afirmar que un acto es bueno o malo se necesita atender a sus tres elementos, a saber: objeto, circunstancias $y$ fin.

En cuanto al objeto, ya se ha señalado que éste es el hecho de educar, y éste no puede ser malo, como acaba de señalarse. Igualmente, se señaló (a. 4) que el objeto es el dato fundamental del acto humano, e incluso se puede decir que "si el objeto es malo, la acción necesariamente será mala ${ }^{38}$, por lo que hasta el momento no puede decirse que el acto educativo sea malo.

Por lo que corresponde a su fin, ya ha quedado claro que la educación es necesariamente buena, pues ayuda al hombre a conseguir su fin último, que es la felicidad. Y en cuanto a las circunstancias, queda claro que mientras más convengan éstas a la naturaleza del hombre y mientras mejores sean desde todos los puntos de vista, mejor será el acto educativo moralmente hablando. En el ejemplo que se describió en a. 6, queda claro que ninguna circunstancia es mala, por lo que ese acto educativo concreto tiene la calificación moral de bueno.

Por último, cabe señalar que la distinción que hace el Aquinate con respecto de los actos interiores de la volun$\operatorname{tad}^{39}$ y los actos humanos exteriores ${ }^{40}$ puntualiza algunas cuestiones importantes del acto educativo, pues éste es un acto interior de la voluntad en el educando, en cuanto que éste debe querer su propia perfección y entonces se logra la autoeducación, y ésta, por lo que se ha señalado, también es necesariamente un acto moralmente bueno. Mientras que en el educador puede apreciarse con más facilidad que el

\footnotetext{
${ }^{38}$ SADA, R. Ética general y aplicada., p. 71

${ }^{39}$ DE AQUINO, T. op. cit., I-II, q. 19.

${ }^{40}$ ibid.., I-II, q. 20.
} 
acto educativo es un acto humano exterior, aunque si en él permanece la intención de educar en el sentido estricto de la palabra, el acto educativo será un acto interior de la voluntad moralmente bueno.

Respuesta a las objeciones.

1. A la primera bay que decir que aun cuando la educación se concreta en una circunstancia no conveniente a la naturaleza del hombre, no puede ser un acto moralmente malo, en cuanto que su fin es siempre el perfeccionamiento del hombre y por ende, la consecución de su felicidad. Así, una educación con alguna circunstancia inadecuada será una educación deficiente, pero nunca mala moralmente hablando.

2. A la segunda bay que decir que la libertad humana no es la elección de cualquier bien, sino del mejor bien en el mejor momento, es decir, la libertad es la autodeterminación al bien, mismo que debe ser conocido previamente por la inteligencia, de manera que el acto voluntario implica pequeños actos de la inteligencia y de la voluntad intercalados sucesivamente ${ }^{41}$. Por tanto, si el acto libre es aquel que tiende al bien y la educación ayuda a que la inteligencia y voluntad posean cada vez con mayor intensidad la verdad y el bien respectivamente, entonces es absurdo pensar que la educación coarta la libertad. Más bien se aprecia que el acto educativo la potencia.

3. A la tercera bay que decir que no hay actos indiferentes según su especie, y si todo acto recibe su especie del objeto ${ }^{42}$ y el objeto de la educación es el hecho de educar, entonces el acto educativo no sólo no es indiferente, sino que es bueno, como ya se anotó. 


\section{BIBLIOGRAFÍA}

- FUENTES:

1. ARISTÓTELES. Ética Nicomáquea / Ética Eudemia. Gredos., Madrid., 1988., 555 p. (versión original 335-322 a.C.). 2. ARISTÓTELES. Obras. Aguilar., Madrid., 1982., 564 p. (versión original 335-322 a.C.).

3. ARISTÓTELES. Metafísica. Gredos., Madrid., 1998., 828 p. (versión original 335-322 a.C.).

4. DE AQUINO, Tomás. Comentario al «Libro del Alma» de Aristóteles. Arché., Buenos Aires., 1979., (versión original 1267-1269).

5. DE AQUINO, Tomás. Suma contra gentiles. Biblioteca de Autores Cristianos., Madrid.,1967., 516 p. (versión original 1259-1264).

6. DE AQUINO, Tomás. Suma Teológica. Biblioteca de Autores Cristianos., Madrid., 1988. (versión original 1266-1273).

COMENTADORES/OTRAS OBRAS:

1. AlvirA, Tomás. ClAVELl, Luis. MELENDO, Tomás. Metafísica. EUNSA., Pamplona., 1989., 247 p.

2. ALTAREJOS, Francisco. Educación y felicidad., EUNSA., Pamplona., 1986., 156 p.

3. CARDOnA, Carlos. René Descartes: El discurso del método. EMESA., Madsrid., 1975., 158p.

4. CHOZA, J. Manual de antropología filosófica., RIALP., Madrid., 1988., 496 p.

5. GARCÍA HOZ, Víctor. Principios de Pedagogía Sistemática. RIALP., Madrid., 1960., 485 p.

6. MILLÁN PUELLES, A. La formación de la personalidad humana., RIALP., Madrid., 1989., 216 p. 
7. NAVAL, Concepción. Educación, retórica y poética: Tratado de la educación en Aristóteles. EUNSA., Pamplona., $629 \mathrm{p}$.

8. ROUSSEAU, Juan Jacobo. Obras completas. Tomo IV: Emilio, Educación, Moral, Botánica., Biblioteca de la Pléyade., París., 1969.

9. SADA, Ricardo. Ética general y aplicada. Mi-Nos., México., 234 p. 